$$
\begin{aligned}
& \text { جامعـة المنصسـورة } \\
& \text { كليـــة التربية }
\end{aligned}
$$

دور مدراء مدارس المرحلة المتتوسطة في تفعيل النرعة

الاجتماعية لدى طلاب المدربسة بدولة الكويت هن

وجهة نظر المهملميدن

$$
\begin{aligned}
& \text { إعداد } \\
& \text { دا طلال عجيل الفضلي } \\
& \text { موجه فني لمادة الاجتماعيات }
\end{aligned}
$$

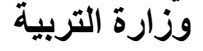

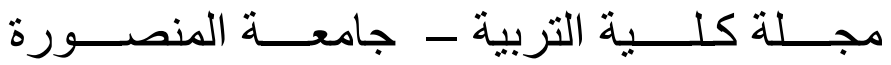

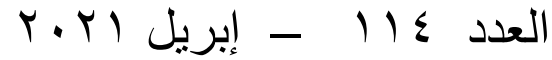




\title{
دور مدراء مدارس المرحلة المتوسطة في تفعيل النزعة الكوبة الاجتماعية لاى طلاب المدرسة بدولة الكويت من وجهة نظر المئولئل المعلمين
}

\author{
دا طلال عجيل الفضلي \\ موجه فني لمادة الاجتماعيات

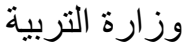

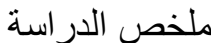

$$
\begin{aligned}
& \text { هدفت الدراسة إلى التعرف على دور مدراء مدارس المرحلة الهتوسطة في تفعيل النزعة الاجتماعية } \\
& \text { للى طلاب المدرسة بدولة الكوبت من وجهة نظر المعلدين ، والكثف عن الفروق لاستجابات أفراد عينة }
\end{aligned}
$$

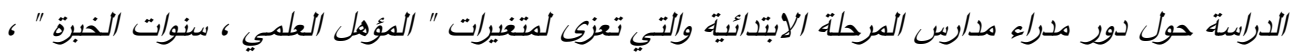

$$
\begin{aligned}
& \text { وتكونت عينة الدراسة من معلمي ومعلدات مدارس المرحلة الدتوسطة التابعة لمنطقة الأحمدي التعليية بدولة } \\
& \text { الكويت ، وقد بلغ قوامها (·11) معلم ومعلدة ، وقد اعتد الباحث على الدنهج الوصفي التحليلي لمناسبته }
\end{aligned}
$$

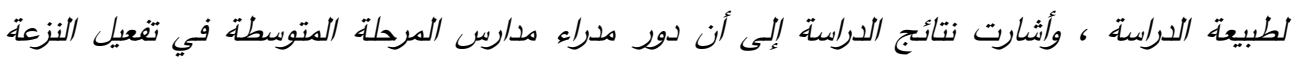

$$
\begin{aligned}
& \text { الاجتماعية لدى طلاب الددرسة بدولة الكويت جاء بتقدير متوسط ، بالإضافة إلى وجود فروق دالة إحصائية }
\end{aligned}
$$

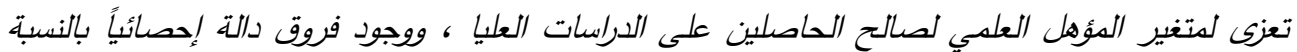

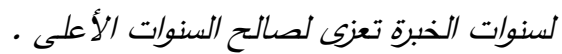

$$
\begin{aligned}
& \text { الكلمات الدفتاحية : النزعة الاجتماعية ، ددراء ددارس المرحلة المتوسطة }
\end{aligned}
$$

\section{Abstract}

The Research aimed to study the role of managers' preparatory schools to activate sociable for students at Kuwait state of teachers' vision, revealing the differences about the role of managers' preparatory schools according to qualification, and years of experience, the sample of this research including (110) teachers of preparatory schools at El-Ahmadi educational district in Kuwait state, and the researcher used descriptive analytical method. The results revealed the role of managers' preparatory schools to activate sociable for students at Kuwait state with moderate rating, in additional to the statistical significant differences according to qualification to postgraduate studies, and there were statistical significant differences according to years of experience to the highest years.

Keywords: sociable, managers' preparatory schools 
لايمكن للإنسان العيش بصورة منفصلة عن مجتمعه، فهما يتفاعلان ضمن علاقة تبادلية،

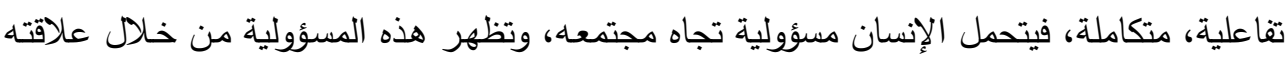
بأفراد مجتمعه الآخرين والطريقة التي يتفاعل فيها معهم. تعتبر المسؤلية الاجتماعية بمثابة الدعامة للحياة المجتمعية ووسيلة للتتمية الفردية والجماعية، فالفرد يأخذ قيمته من درجة تحمله للمسؤولية

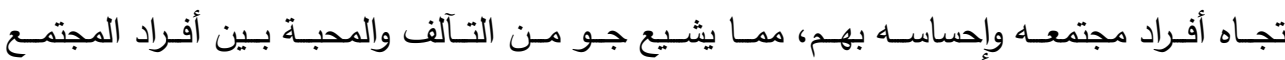

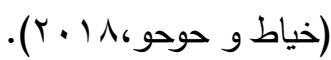
يميل الإنسان بصورة عامة نحو الجماعة كطريقة لتعويض الضعف الطبيعي الذي يشعر به،

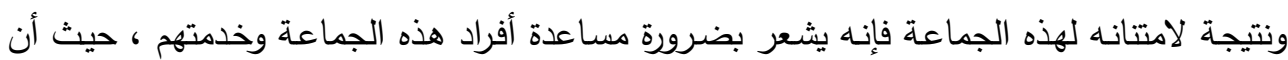
ممارساته وتصرفاته لا تتصب في خدمة ذاته فقط بل تنفتح على الجماعة، وهذا ما يعرف بالنزعة

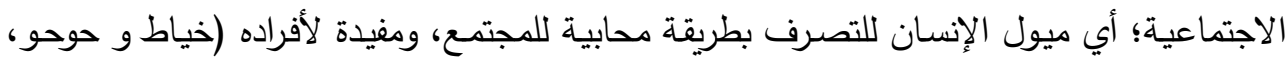
Rodrigues, Ulrich, Mussel, Carlo, \& Hewig, 2017; Longobard, ؛r.।^ Settanni, Lin, \& Fabris, 2020) وتعد الددرسة واحدة من أهم مؤسسات المجتمع المحلي التي تقوم بدور هام جداً في التتشئة

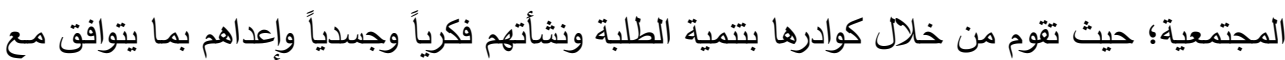
الصـالح العام، فالمدرسة هي المسؤول عن ترسيخ القيم والمبادئ الاجتماعية وتمكينها في نفوس

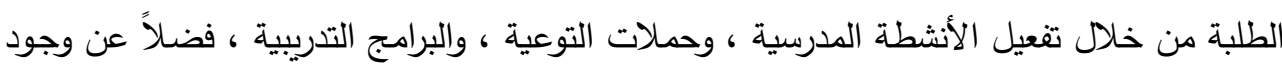

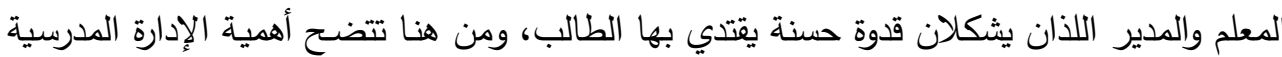
-المتمثلة بصـورة أساسية في شخصية مديرها- ودورهـا في تعزيز إداك الطالب لواجباتـه تجـاه مجتمعه، وتتمية قدرته على المشاركة الفعالة في تطويره، وتمكين القيم المجتمعية، وتعزيز انتماءه له

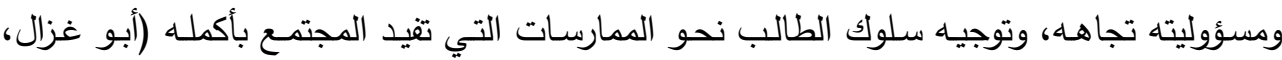

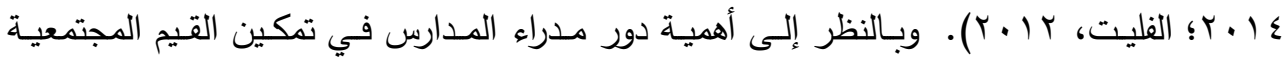

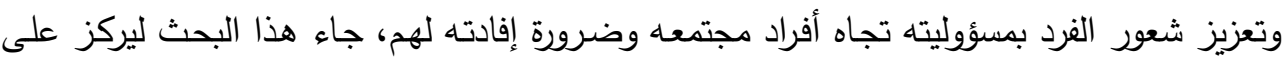
دراسة دور مدراء مدارس المرحلة المتوسطة في تفعيل النزعة الاجتماعية لاى طلاب المدرسة. مشكلة البحث و أسئلته يمكن المحافظة على الحياة الاجتماعية من خلال التعايش بصورة سليمة مـع أفراد المجتمع وتكوين علاقات إيجابية متوازنة معهم، حيث أن الإنسان لا يعيش بهدف تحقيق مصالحه وحده بل

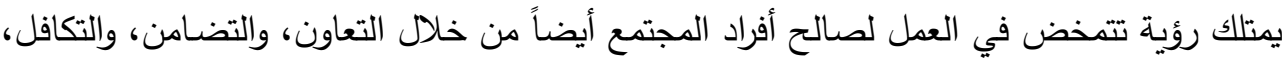
والتعاطف معهم (Aytaç \& Kartal, 2016) • وتساهم السلوكيات الدحابية للمجتمع الناشئة عن 
وجود نزعـة اجتماعيـة عند الفرد على تحقيق استقراره وطمأنينـة أفراده وشيوع حالـة مـن المحبـة والصداقة فيما بينهم، وعند وجود نزعة اجتماعية لدى الأفراد فإنهم يكرسون أنفسهم لمساعدة الآخرين

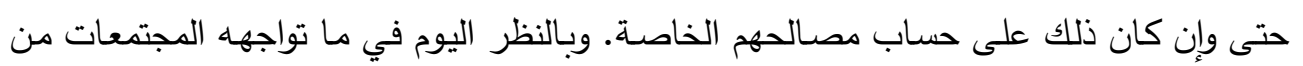

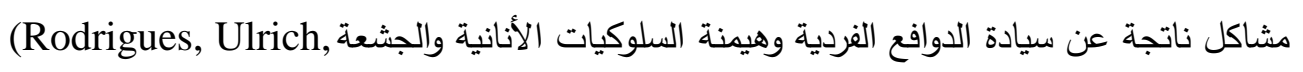
ونظراً لأهمية دور مدير المدرسة في التأثير في سلوكيات طلاب مدرسته وترسيخ انتمائهم لمجتمعاتهم وتتمية إحساسهم بالمسؤولية تجاهها، وإحساس الباحث

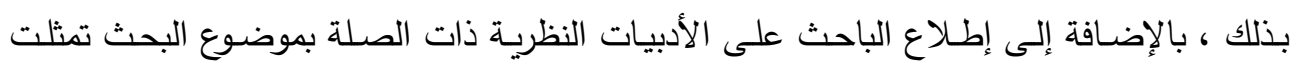

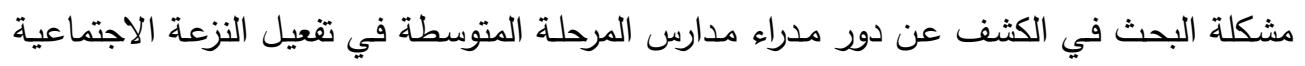
لاى طلاب المدرسة ، ومن ثم تلخصت مشكلة البحث في السؤال الرئيس التالي :

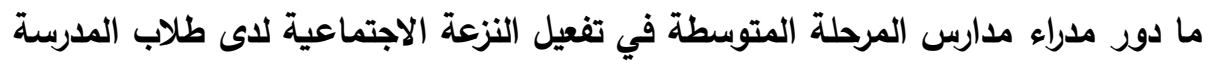

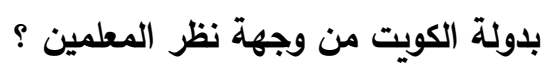

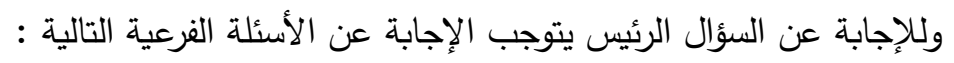

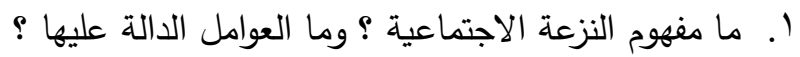

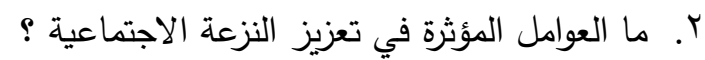

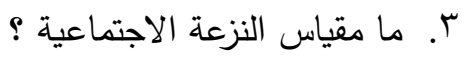
ـ. مـا دور مدراء مدارس المرحلة المتوسطة في تفعيل النزعة الاجتماعية للى طلاب المدرسة من وجهة نظر المعلمين ؟

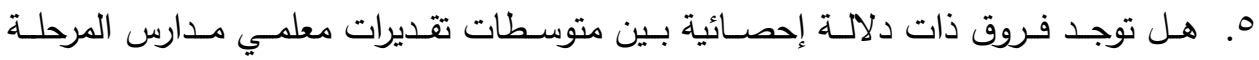

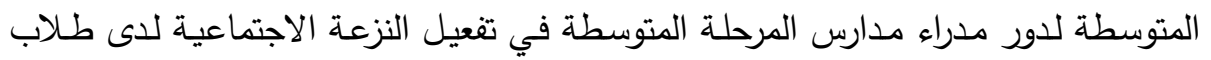
المدرسة تعزى لمتغيرات (المؤهل العلمي وسنوات الخبرة )من وجهة نظر المعلمين ؟ أهداف البحث :

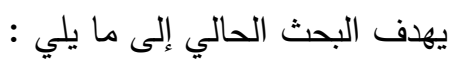

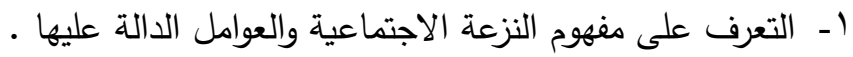

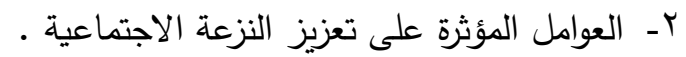
r- التعرف على الفروق في استجابات أفراد عينـة الدراسـة حول دور مدراء مدارس المرحلـة

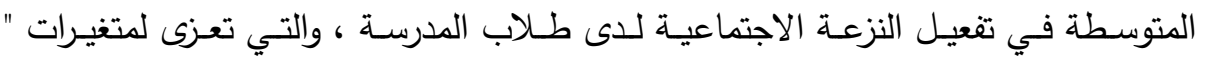
الجنسية ، المؤهل العلمي، سنوات الخبرة " من وجهة نظر المعلمين . أهمية البحث 


$$
\text { تتبع أهمية البحث الحالي من الأمور التالية : }
$$

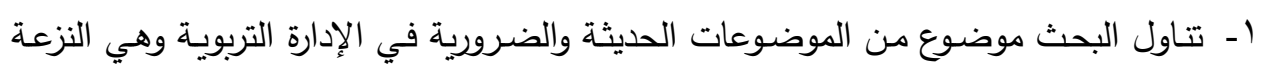

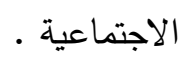

r- أن يسهم البحث الحالي في الإثراء المعرفي في هذا المجـال وإضـافة المكتبـة العربية بمـا

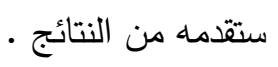

r- أن يساعد البحث الحالي مدراء مدارس المرحلة المتوسطة بدولة الكويت في الاهتمام بتمية

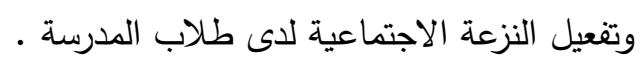

$$
\text { حدود البحث }
$$

- الحد الموضوعي: اقتصر البحث الحالي على قياس دور مدراء مدارس المرحلة المتوسطة في تفعيل النزعة الاجتماعية لدى طلاب المدرسة بدولة الكويت من وجهة نظر المعلمين . - الحـد البثـري: تم تطبيق البحث الحالي على جميع معلمي ومعلمـات جميع مدارس المرحلة

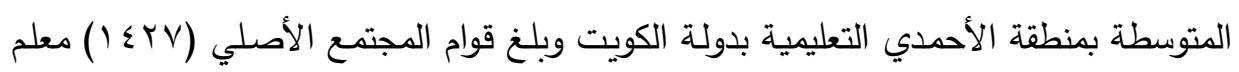

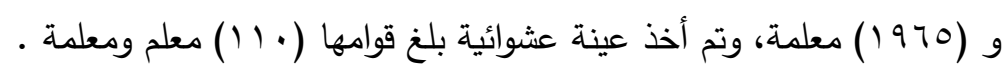
- الحد المكاني: تم تطبيق البحث الحالي على جميع مدارس المرحلة المتوسطة ل لمنطقة الأحمدي

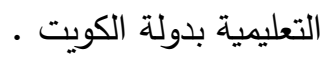

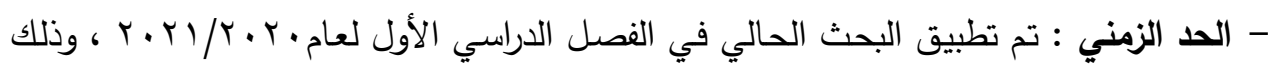

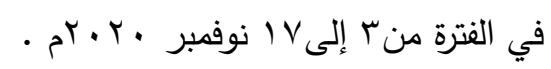
مصطلحات البحث

النزعة الاجتماعية: هي عمل تطوعي يقوم به الفرد لإفادة شخص آخر ومساعدته ، والتي

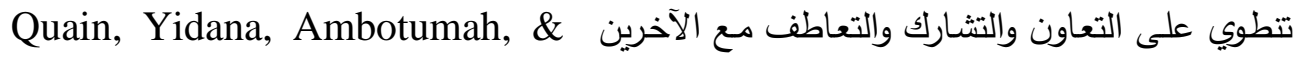
Mensah-Livivnstone, 2016; Plenty, Ostberg, \& Modin, 2015) ويعرفها الباحث إجرائياً على أنها شعور طلاب مدارس المرحلة المتوسطة بدولة الكويت بالانتماء إلى مجتمعهم والتطوع لإفادة الآخرين والتعاون معهم والتثارك فيما بينهم ومساعدة الدحتاج الدر اسات السابقة

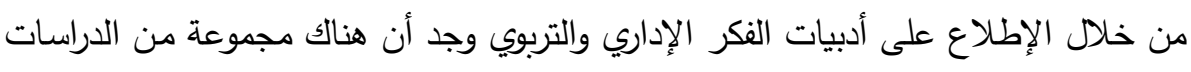
التي تتناول النزعة الاجتماعية في المجال التربوي ، وذلك على النحو التالي : 
- دراسة (Gao, Yao, Yao, Xiong, Ma,\&Liu, 2019) بعنوان "حالة النزعة الاجتماعية

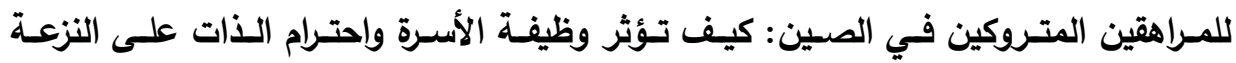

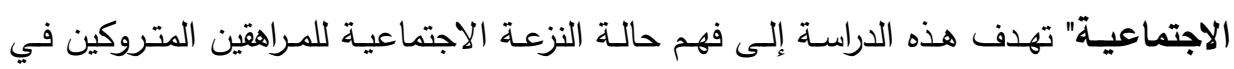
الصين والتعرف على كيفية تأثير الأسرة واحترام الذات على النزعة الاجتماعية. اعتمد الباحث

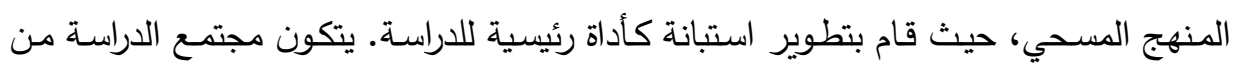

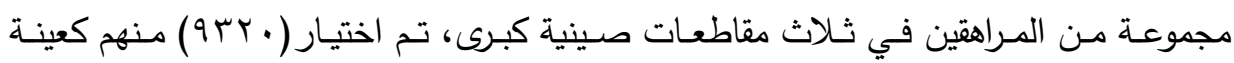

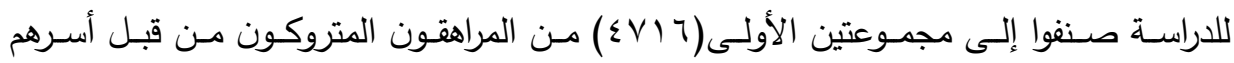

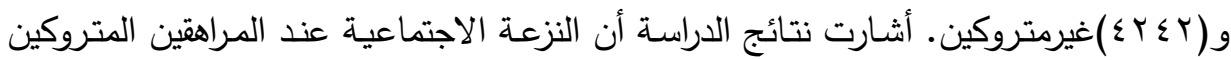

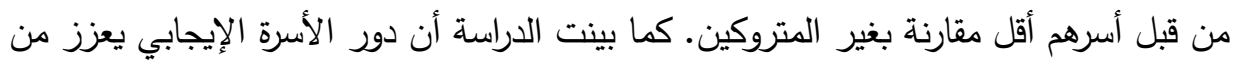

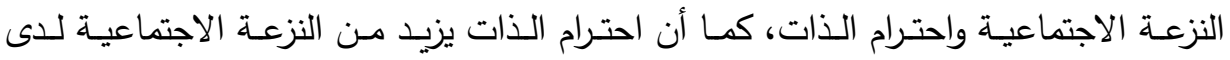

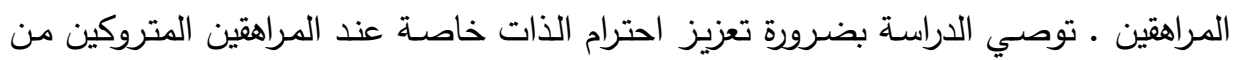
قبل أسرهم لتعزيز الجانب النفسي والاجتماعي لديهم. توفئ. - دراسـة (Aytaç \& Kartal, 2016) بعنوان "تحليل الاتجاه الاجتمـاعي الإيجابي للطلاب

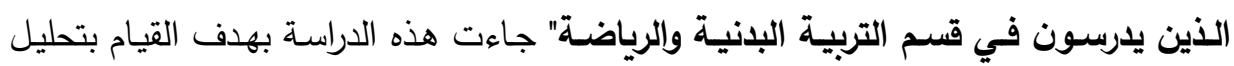

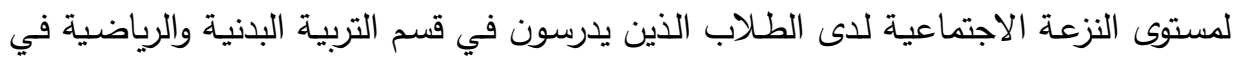
إحدى الجامعات التركية. اعتمد البحث على المنهج الوصفي التحليلي، حيث تم استخدام مقياس النزعة الاجتماعية (PSBTS-Positive Social Behaviors Tendency Scale) والذي لنكي يتكون من ست أبعاد أساسية ؛ السلوك الاجتماعي العام، العاطفي، الدحب للغير (الإيثار)،

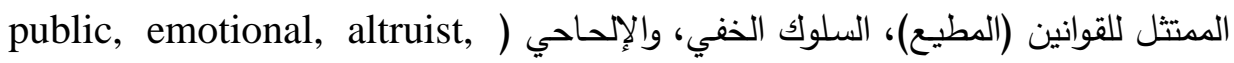
(obedient, hidden and urgency البكالوريوس والدراسات العليا في قسم التربية البدنية والرياضية في إحدى الجامعات التركية، تم

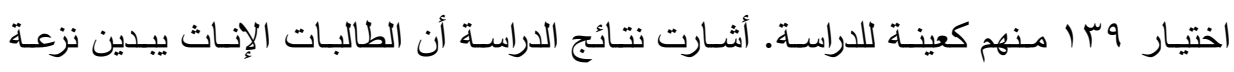
اجتماعيـة أعلى من الذكور في مقيـاس النزعـة الاجتماعيـة (PSBTS) في كل من الأبعاد

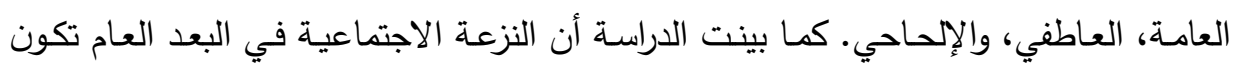

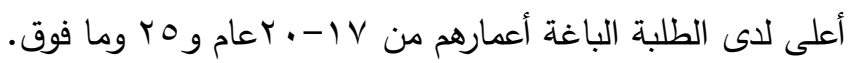
- دراسـة (Lampridis \& Papastylianou, 2014) والتوجه نحو الفردية - الجماعية للشباب اليونانيين" جاءت هذه الدراسة بهدف التحقيق من 
النزعـة الاجتماعيـة الإيجابيـة للشباب اليونـاني والكثف عن العلاقـة بين النزعـة الاجتماعيـة

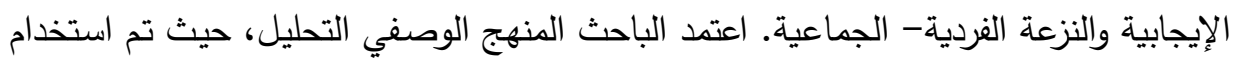

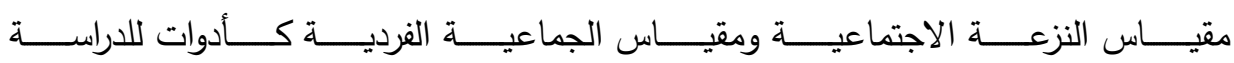
ProsocialTendencies Measure and the Auckland's Individualism ) (Collectivism Scale

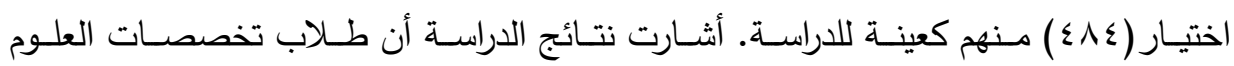

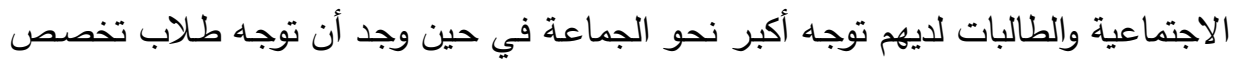

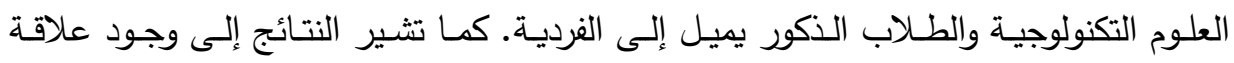

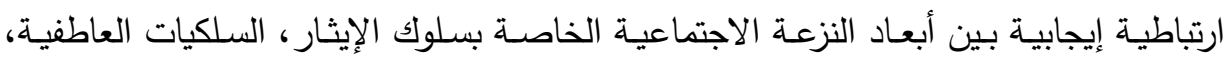

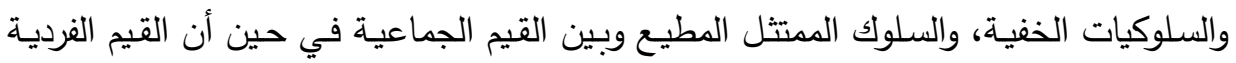
مرتبطة بالبعد العام للنزعة الاجتماعية.

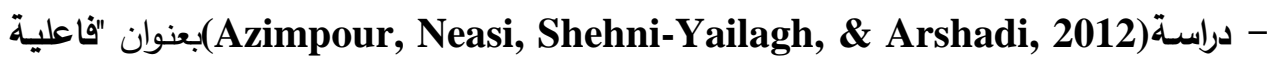

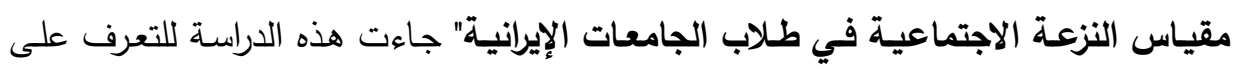
صحة مقياس النزعة الاجتماعية (Prosocial Tendency Measure-PTM) في الطلاب الإيـرانيين. والذي يقيس سـت أبعـاد للنزعـة الاجتماعيـة، تثــل: النزعـة الاجتماعيـة العامـة،

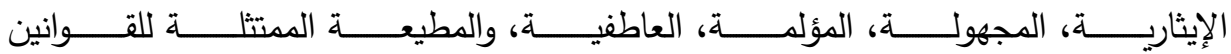
altruistic,anonymous, dire, emotional, compliant and public prosocial ) (tendencies الاجتماعيـة كأداة للدراسـة. يتكون مجتمـع الدراسـة من طـلاب الجامعـات الإيرانيـة، تم اختيار

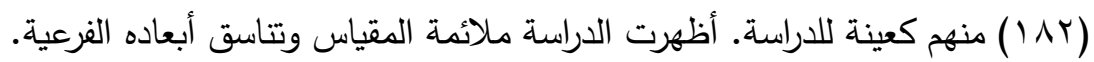

\section{الإطار النظري \\ النزعة الاجتماعية}

تثير النزعة الاجتماعية إلى السلوكيات الإيجابية المحابية للمجتمع ويقصد بها ما يتم القيام به تطوعاً لصالح أفراد المجتمع ، وهي ميل الإنسان نحو التصرف بصورة إيجابية ومساعدة للآخرين 
في مواقف محددة كالتبرع بالمـال للمحتاجين، ومسـاعدة المسنين، والتعاون في تتظيف الحي ، والتقاط الأذى عن الطريق(Aytaç \& Kartal, 2016).

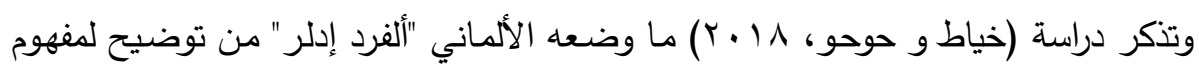

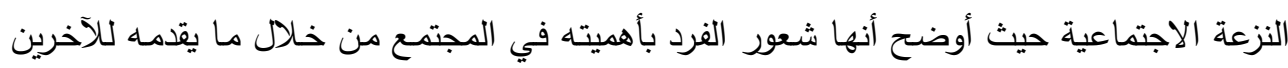

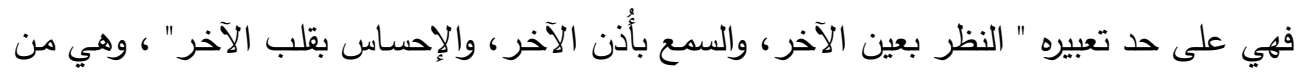

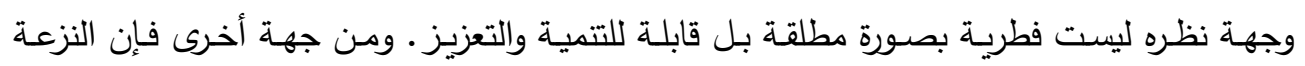

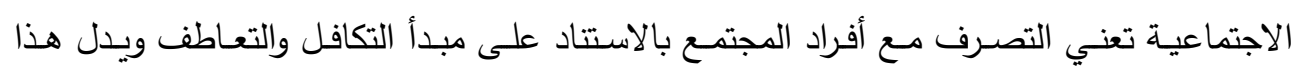

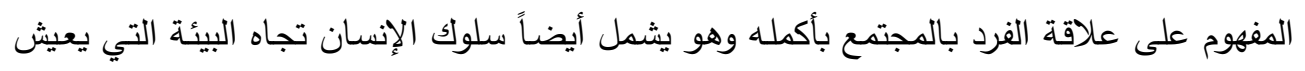

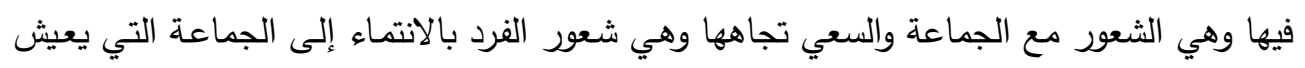

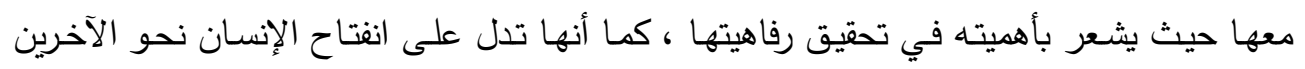
وتكريس سلوكه لمساعدتهم بدلاً من تركيزه على ذاته.

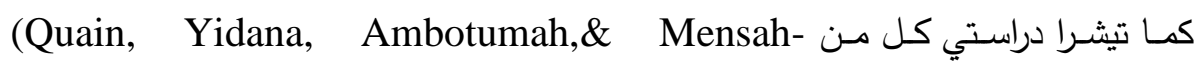
Livivnstone, 2016; Plenty, Ostberg, \& Modin, 2015) على أنها عمل تطوعي يقوم به الفرد لإفادة شخص آخر ومساعدته ، والتي تتطوي على التعاون والتشارك والتعاطف مع الآخرين.

وهنا يجب الإشـارة إلى نقطتين ؛ الأولى أن النزعة الاجتماعية لا تثير إلى نفس مفهوم

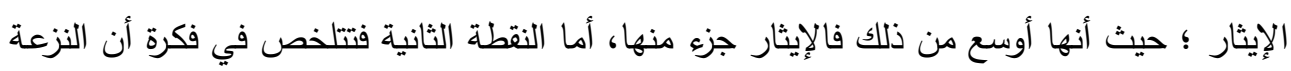

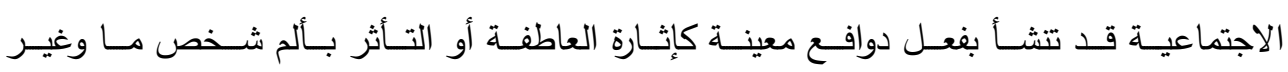
ذلك)(Lampridis \& Papastylianou, 2014).

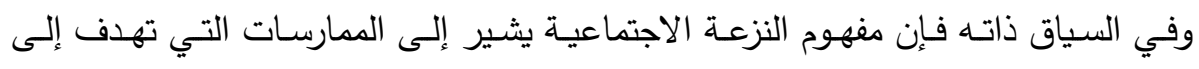

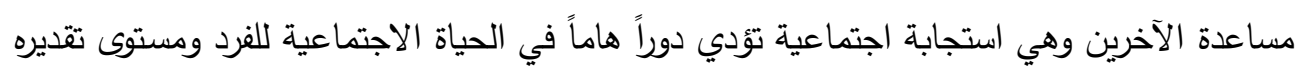
لذاته) (Hardy, Carlo, \& Roesch, 2010)

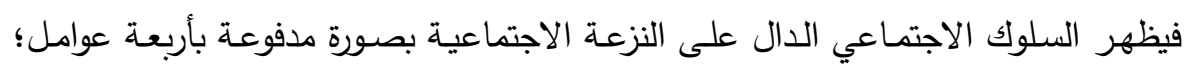

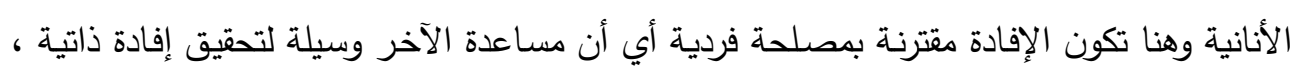

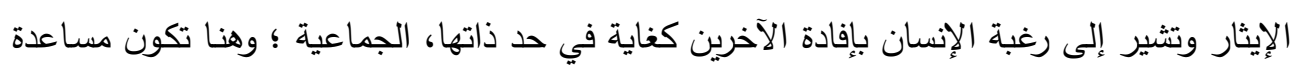

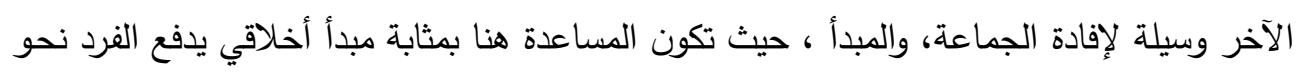
إظهار نزهة اجتماعية(Lampridis \& Papastylianou, 2014). 
ومن المهم تعزيز النزعة الاجتماعية عند طلبة المدارس ، حيث يميلون في الغالب إلى تقليد

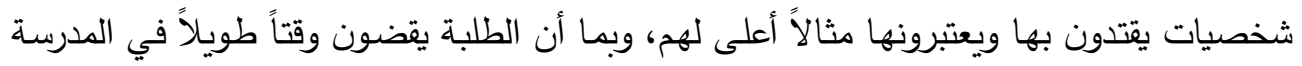

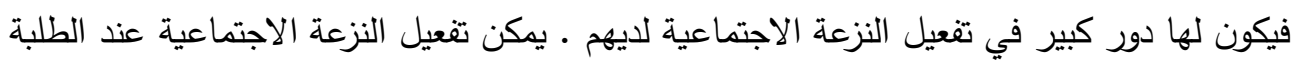

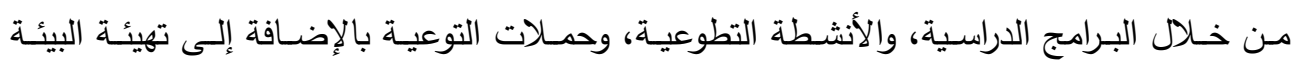
المدرسية بالعناصر المغذية للقيم والمبادئ التي تثكل المنظومة الأخلاقية (Kuswendi, 2019). وهذا ما تؤكده دراسة (Caprara, et al., 2014) والتي أشارت إلى أن المدرسة هي بيئة اجتماعية تلعب دوراً كبيراً في تعزيز النزعة الاجتماعية من خـلال تتمية الممارسـات التثـاركية، والتعاونيـة،

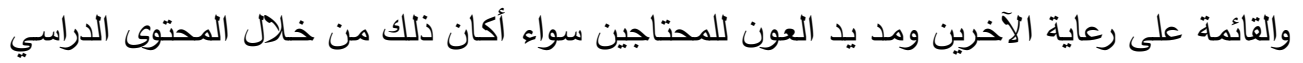

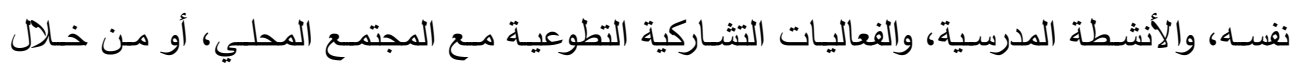
الاقتداء بشخصيات المعلمين والمدراء. مقياس النزعة الاجتماعية

(Azimpour, Neasi, Shehni-Yailagh, \& Arshadi, استخدمت دراسة كل من التعاعة 2012; Rodrigues, Ulrich, Mussel, Carlo, \& Hewig, 2017; Lampridis \& (The prosocial tendencies measure -PTM) مقياس يسمىPapastylianou, 2014) والذي أعد من قبل الباحثين خطأ! لـ يتم العثور على مصدر المرجع. ، يضم هذا المقياس ستة

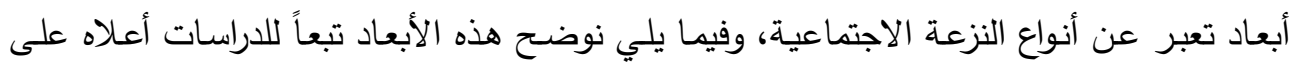

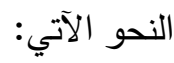

ا. السلوك الإيثارية (Altruism): ويقصد بها المساعدة الطوعية التي يحفزها في المقام الأول

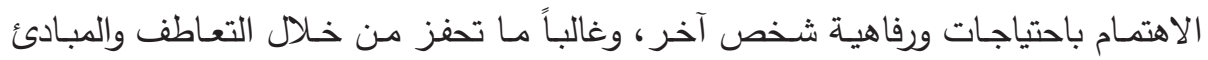
الأخلاقية وهو أحياناً ما ينتج عنها تكلفة الثخص الأهر المساعد بتكلفة ما. r. السـلوك المتوافـق أو المستجيب (compliant): ويقصد بـه مسـاعدة الآخرين كاستجابة لطلب شفهي أو غير شفهي. ومـن المتوقع أن يحدث بشكل متكرر أكثر مـن المسـاعدة التلقائية، وتظهر من خلال عدم تردد الثخص في مساعدة الآخرين عند طلب ذلك.

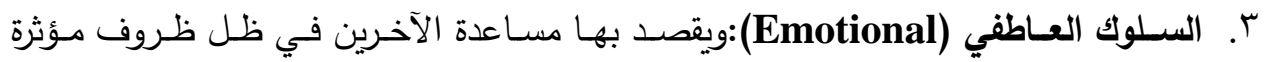
عاطفياً، وهنا فإن وجود موقف يثير العواطف والذكريات يحفز الفرد على تقديم المساعدة للآخرين، وهنا يميل الإنسان إلى مساعدة الآخرين، عند ارتباط الحدث بمؤشرات وذكريات تثير عواطفه. 
ع. السلوك شعبي (Public): ويقصد به سلوك المساعدة التي يتم القيام به على العلن بدافع

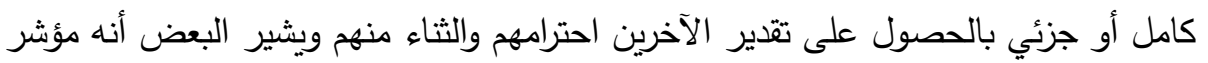
سلبي حيث أن الإنسان هنا يظهر مستوى أكبر من المساعدة للآخرين عندما يشاهده الناس.

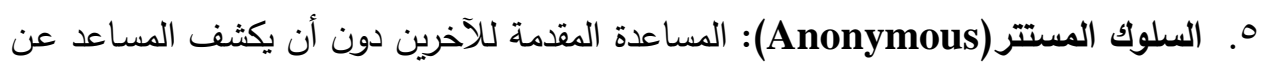

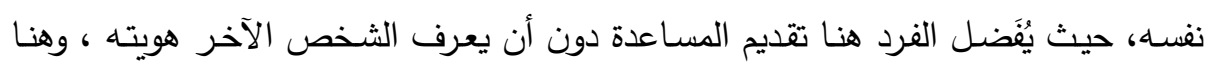

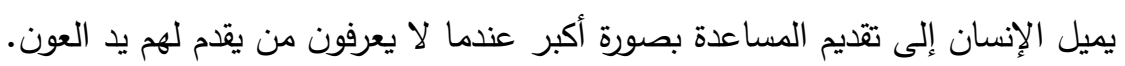

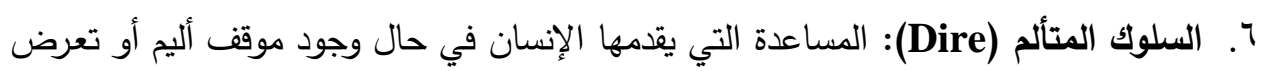

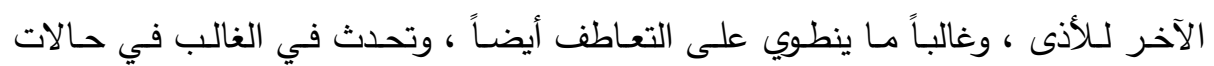

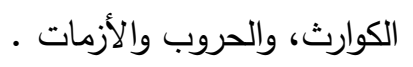

الإدارة المدرسية

تعد الإدارة المدرسية وسيلة لتتظيم جهود الكادر المدرسي وتوجيهها نحو تحقيق عملية تتموية

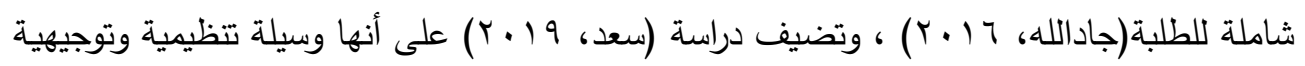
لسلوك عناصر العملية التعليمية نحو تحقيق أهداف المدرسة وتعزيز طلابها وتتميتهم بصورة شاملة

ومتكاملة بالاعتماد على ميولهم، ورغباتهج، وقدراتهم، واستعدادهم والظروف التي يعيشون فيها.

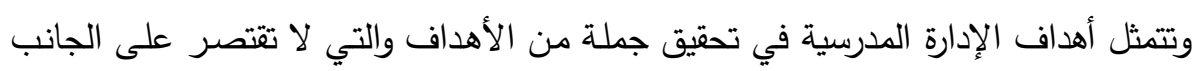
التعليمي وحسب بل تثمل العديد من الجوانب الأخرى؛ ففي المجال الثقافي والتربوي تهدف الإدارة

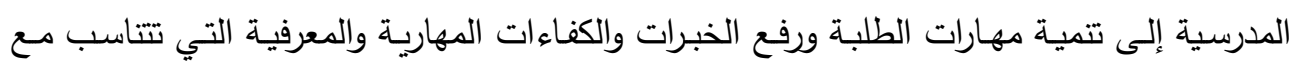

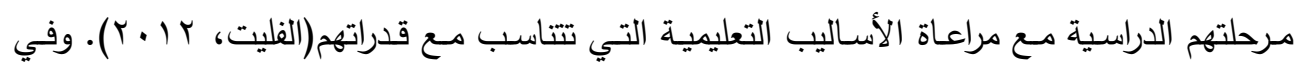

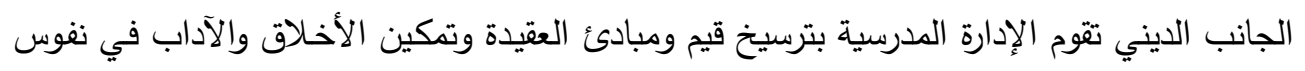
الطلبة وتعزيزها بالمواقف العملية، كما تهتم بالجانب الاقتصادي حيث تهدف إلى إلى رفع مستوى الوعي الوني

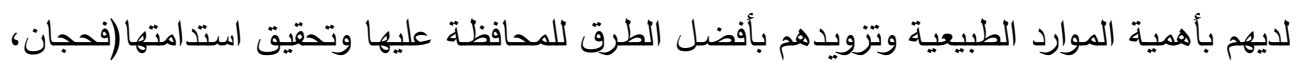

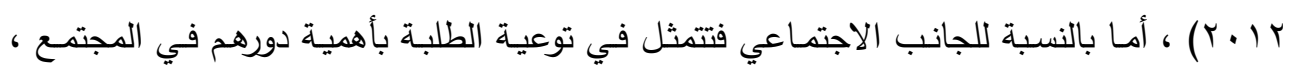

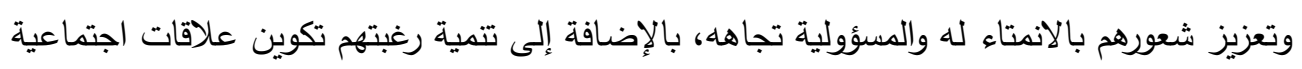

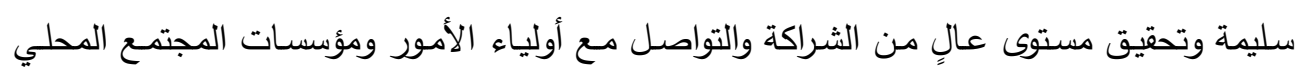

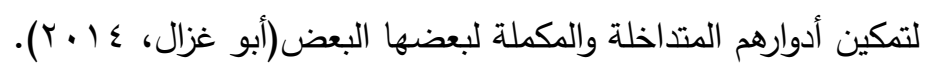

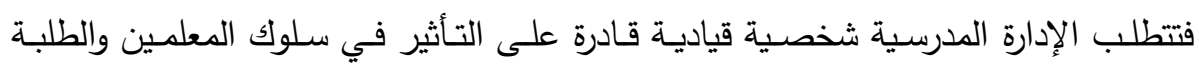

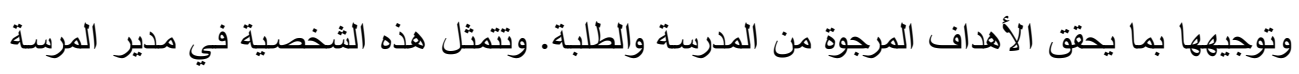


والذي ينبغي أن يكون مدركاً لما يواجهه وقادراً على التأثير بالطلبة والمعلمين والإدارين(الفليت،

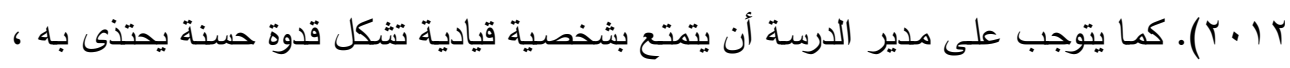

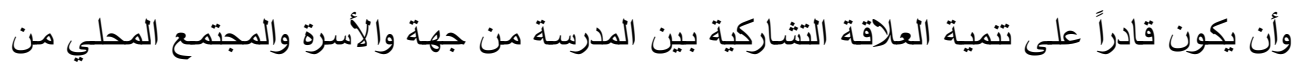

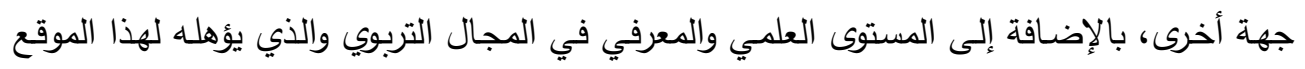

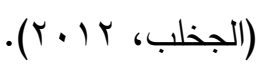
منهجية البحث و إجر اءاته :

$$
\text { منهج البحث : }
$$

استخدم الباحث في هذه البحث المنهج الوصفي التحليلي ، وذلك لمناسبته للتعرف على دور

مدراء مدارس المرحلة المتوسطة في تفعيل نزعة الاجتماعية لدى طلاب المدرسة بدولة الكويت .

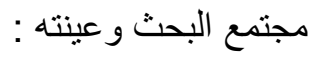

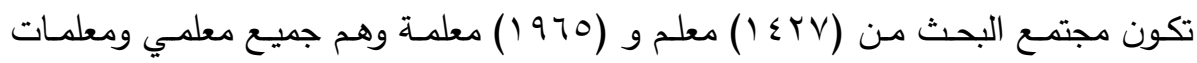
جميع مدارس المرحلة المتوسطة بمنطقة الأحمدي التعليمية بدولة الكويت ـ وبعد تطبيق أداة الدراسة

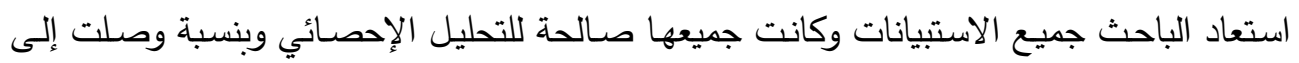

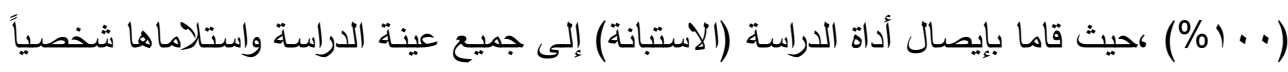

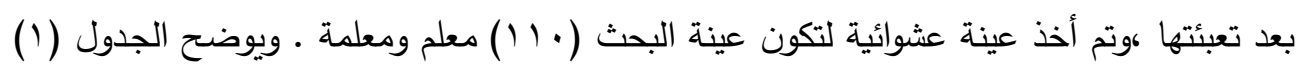
وصف عينة الدراسة طبقاً للخصائص الديموجرافية وعددهم ( • (1) استبانة . جدول ( ) وصف عينة الدراسة

\begin{tabular}{|c|c|c|c|}
\hline \multicolumn{2}{|c|}{ الخصائص الديموجرافية لعينة الدراسة } & 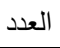 & $\%$ \\
\hline \multirow[t]{2}{*}{ المؤهل العلمي } & جامعي & vo & $\uparrow \Lambda, r$ \\
\hline & دراسات عليا & ro & r, \\
\hline \multirow[t]{3}{*}{ سنوات الخبرة الخبر } & أقل من ه سنوات & 17 & $1 \leqslant, 0$ \\
\hline & من ه إلى · ل سنوات & $0 \leqslant$ & r \\
\hline & أكثر من • 1 سنوات & $\varepsilon$. & $\sum १, 1$ \\
\hline
\end{tabular}

$$
\text { تصميم و إعداد أداة الدر اسة : }
$$

لقد مر تصميم وإعداد أداة الدراسة الميدانية بعدة مراحل ، وذلك على النحو التالي :

أ- تصميم أداة الدراسة : 
بنـاء على طبيعـة الدراسـة،والمنهج المتبع ، والإمكانـات المتاحسة المادية والزمنيـة ، استخدم

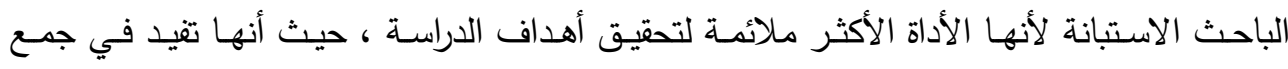

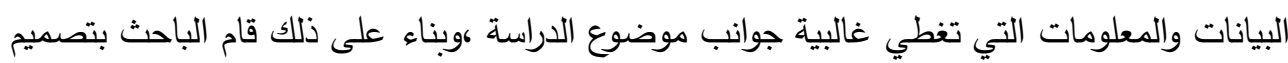
الاستبانة معتمد في ذلك على الآتي:

ا الإطلاع على الأدبيات العلمية ، ومراجعة الدراسات السابقة والتي اهتمت بجانب من جوانب

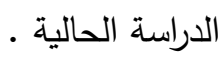

• النقاش مع بعض مدراء ومعلمي مدارس المرحلة المتوسطة بمنطقة الأحمدي للاستفادة من

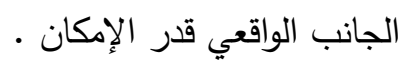

ومن خلال ما سبق تمكن الباحث من تجميع وصياغة مجموعة من العبارات تمثل الاستبانة بصـورتها الأولية وجاءت في (10) عبارة ـ وبنـاء على ملاحظـات المحكمين وتوجيهاتهم تمكن

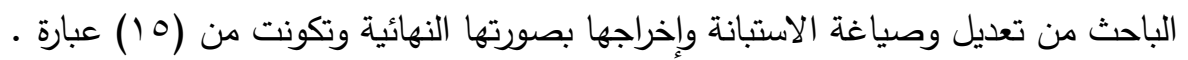
وقد تكونت الاستبانة من قسمين :

القسم الأول: وقد شمل البيانات الأساسية لعينة الدراسة من حيث المؤهل العهل العلمي ، وعدد سنوات الخبرة .

القسم الثاني:وشمل على عبارات تحتوي على دور مدراء مدارس المرحلـة المتوسطة في تفعيل النزعة الاجتماعية لاى طلاب المدرسة بدولة الكويت :

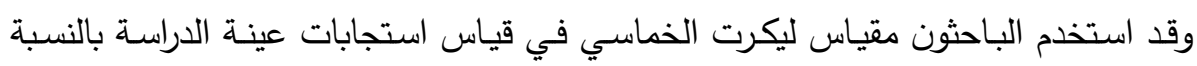

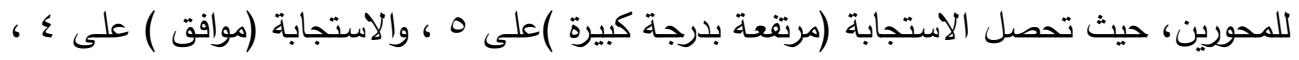

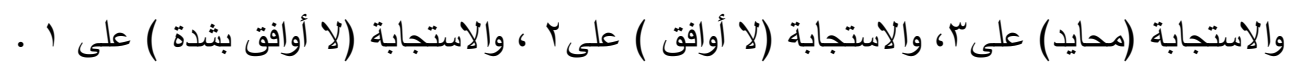

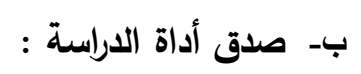

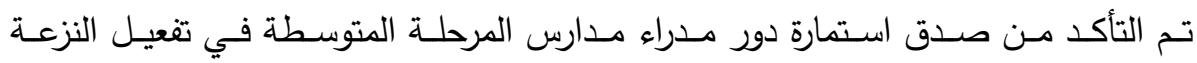
الاجتماعية لدى طلاب المدرسة في دولة الكويت ، وذلك بطريقتين على النحو التالي : صدق المحتوى: وذلك بعرض الاستمارة في صـورتها الأوليـة على المحكمين (ن= (1)

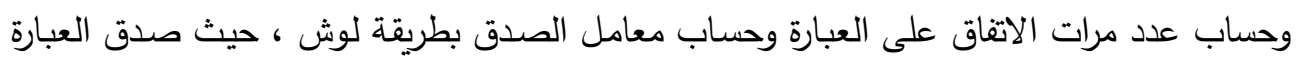

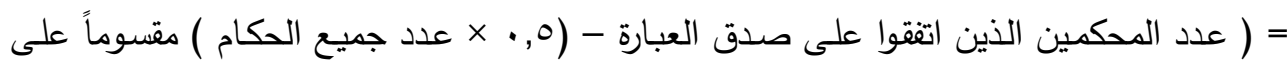

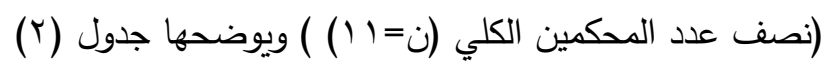
1 - صدق الاستبيان 
جدول (ץ) معاملات الصدق لعبارات الاستبانة بطريقة لوش (ن= I ( )

\begin{tabular}{|c|c|c|c|}
\hline رقم العبارة & معامل الصدق & رقم العبارة & معامل الصدق \\
\hline 1 & $V Y, V Y$ & 11 & $V Y, V Y$ \\
\hline$r$ & $\wedge 1, \wedge 1$ & Ir & $\wedge 1, \wedge !$ \\
\hline$r$ & $1 \ldots, \ldots$ & $1 \pi$ & $1 \ldots, \ldots$ \\
\hline$\varepsilon$ & $9 ., 9$. & $1 \varepsilon$ & $1 \ldots, \ldots$ \\
\hline 0 & $1 \ldots, \ldots$ & 10 & $1 \ldots, \ldots$ \\
\hline 7 & $1, \cdot, \cdot$ & & \\
\hline $\mathrm{V}$ & $9 ., 9$. & & \\
\hline$\Lambda$ & $\wedge 1, \wedge 1$ & & \\
\hline 9 & $V Y, V Y$ & & \\
\hline 1. & $1 \ldots, \ldots$ & & \\
\hline
\end{tabular}

تم حسـاب صدق المحكمين بطريقة لوش بعد جمع وصياغة عبارات المقيـاس، وعرضـــ بصورته الأولية المكونة من 10 عبارة على مجموعة من المتخصصين وذلك للتأكد من صلاحية

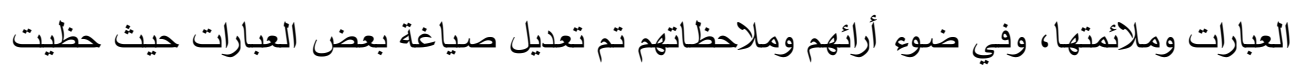

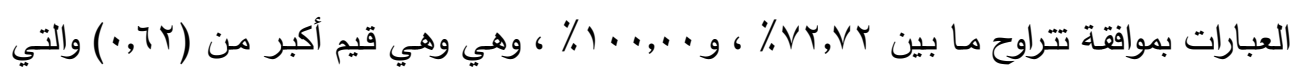
حددتها طريقة لوش مما يدل على صدق العبارات . كما تم التأكد من صدق الاستمارة بحساب معامل الارتباط بين درجة العبارة والدرجة الكلية

للمقياس ويوضحها جدول (r) •

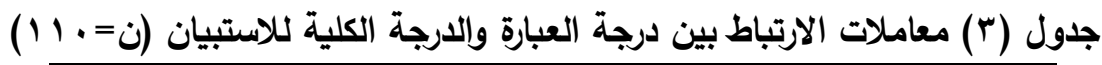

\begin{tabular}{|c|c|c|c|}
\hline رقم العبارة & معامل الارتباط & رقم العبارة & معامل الارتباط \\
\hline 1 & $* * *, \neg \wedge r$ & 11 & $* * *, 741$ \\
\hline r & $* * *, V Y I$ & Ir & $* * *, V \leq \leq \leq$ \\
\hline$r$ & $* * *,, \uparrow, \Lambda$ & $1 \pi$ & $* * *, 009$ \\
\hline$\varepsilon$ & $* * *, 091$ & $1 \leqslant$ & $* * *, 0 \leq 1$ \\
\hline 0 & $* * *,, \vee \curlyvee q$ & 10 & $* * *, V \backslash \leq$ \\
\hline 7 & $* * *, V Y V$ & & \\
\hline V & $* * *, 099$ & & \\
\hline$\Lambda$ & $* * *, 0,7$ & & \\
\hline 9 & $* * *,, 4 \wedge 7$ & & \\
\hline 1. & ****,rr. & & \\
\hline
\end{tabular}

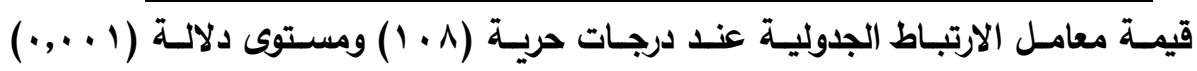

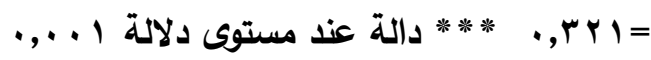


يوضـح جدول (r) أن كل عبارات استبانة دور مدراء مدارس المرحلة المتوسطة في تفعيل النزعة الاجتماعية لاى طلاب المدرسة ارتبطت بمعاملات ارتباط دالة إحصائياً عند مستويات دلالة

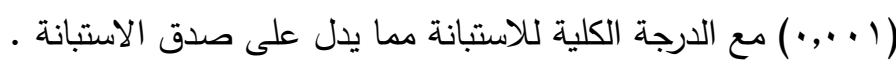
ثبات الاستبانة كما تم التأكد من ثبات عبارات الاستبانة وكذلك ثبات المحاور بطريقة ثبات ألفا لكرونباك .

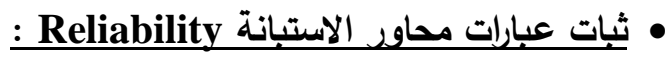

ويقصد بها أن تعطفي نقس النتائج أو نتائج متقاربة ، إذا طبق أكثر من مرة في ظروف الإنه

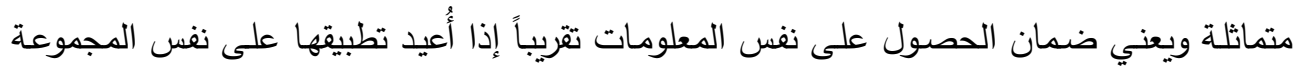

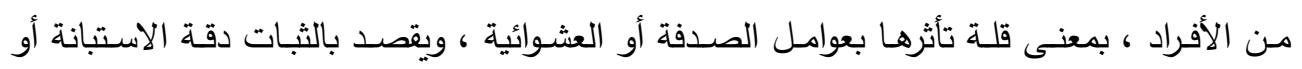

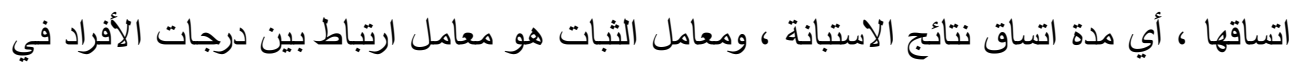
الاستبانة مرات الإجراء المختلفة ، وقد تم حساب ثبات مقياس درجة دور مدراء مدارس المرحلة

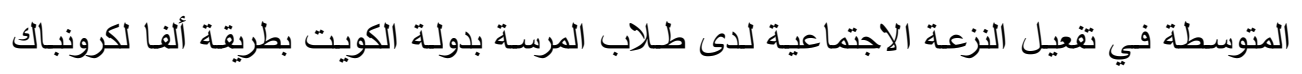

$$
\text { وجدول (乏) يوضح معاملات ثبات ألفا لعبارات الاستبانة . }
$$

جدول (؛ ) معاملات ثبات ألفا لمفردات الاستبانة بطريقة لكرونباك

\begin{tabular}{|c|c|c|c|}
\hline رقم العبارة & معامل الثبات & رقم العبارة & معامل الثبات \\
\hline 1 & $\cdot, \wedge \vee \vee$ & 11 & $\cdot, \wedge \vee \wedge$ \\
\hline$r$ & $\cdot, \wedge \vee \leq$ & ir & $\cdot, \wedge \vee r$ \\
\hline$r$ & $\cdot, \wedge \vee q$ & ir & .,A^r \\
\hline$\varepsilon$ & $\cdot, \wedge \wedge$. & $1 \varepsilon$ & $\cdot, \wedge \wedge r$ \\
\hline • & $\cdot, \wedge \vee \leq$ & 10 & $\cdot, \wedge \vee 0$ \\
\hline 7 & $\cdot, \wedge \vee r$ & & \\
\hline$v$ & $\cdot, \wedge \wedge$. & & \\
\hline$\wedge$ &,$\wedge \wedge \leq$ & & \\
\hline 9 & $\cdot, \wedge \vee \vee$ & & \\
\hline 1. & •, & & \\
\hline
\end{tabular}

يوضح جدول ( ) أن قيم معاملات ألفا كرونباك لعبارات استبيان دور مدراء مدارس المرحلة

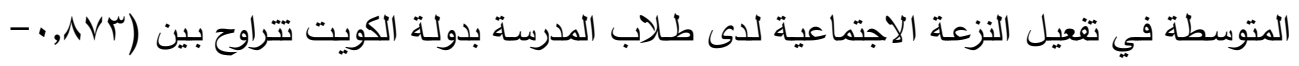
190 > • )، وهي قيم مقبولة وتعد مؤشراً قوياً على ثبات الإستبانه وصلاحيته للتطبيق. جدول (0) معاملات ثبات إجمالي الاستبانة بطريقة الفا لكرونباك

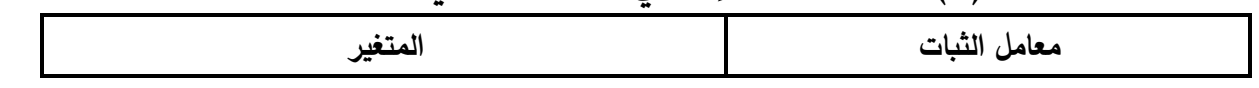




\begin{tabular}{|c|c|}
\hline يوإ & إجمالي تفعيل النزعة الاجتماعية \\
\hline
\end{tabular}

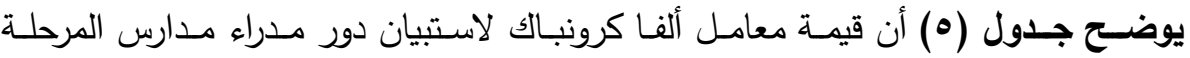

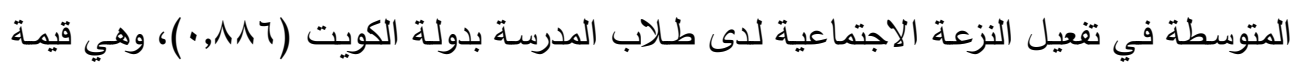
مقبولة وتعد مؤشراً قوياً على ثبات الاستبانة وصلاحيتها للتطبيق. نتائج الدراسة ومناقتشتها أولا: دور مدراء مدارس المرحلة المتوسطة في تفعيل النزعة الإجتماعية لدى طلاب المدرسة من وجهة نظر المعلمين

جدول (7)

الاستجابات حسب متوسطتها الحسابية لإستبيان دور مدراء مدارس المرحلة المتوسطة في تفعيل النزعة الإجتماعية لاى طلاب المدرسة بدولة الكويت من وجهة نظر المعلمين

\begin{tabular}{|c|c|c|c|c|c|c|c|}
\hline ค & 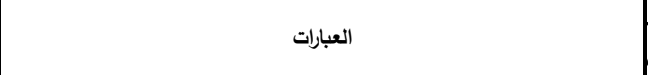 & & 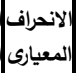 & |قيمة ت والدلالة| & اللنسبة المئوية & 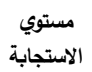 & الترتيب \\
\hline 1 & لـ التعاون- الصداقة ). مدير المدرسة في اجتماعاته مع الطلاب على استخدام مفردات مثل (الحب & $r, r v$ & $\cdot, \wedge r \mathrm{r}$ & $* * * \leqslant r, \cdot 1 r$ & TV, \& & متوسط & 1 \\
\hline r & |نجلب المسابقات التي يقدمها مدير المدرسة يكون الفائز فيها شخص واحد وليس & $r, \leqslant \leqslant$ & $1, \ldots 9$ & 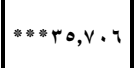 & $\checkmark \wedge, \wedge$ & 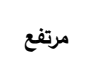 & $\varepsilon$ \\
\hline$r$ & هتم مدير المدرسة بإتمام العمل أكبر من اهتمامه في عدد المشاركين فيه. & $r, r r$ &.,$\wedge \vee \leqslant$ & $* * * \wedge, \vee 10$ & ד, & متوسط & Ir \\
\hline$\varepsilon$ & يثجع مدير المدرسة الطلاب على الثعور بمسؤولية تجاه أسرهم. & $r, r_{0}$ & $\cdot, \wedge \wedge \leq$ & $* * * \sim 9, \wedge \cdot 1$ & iv, & متوسط & $\Lambda$ \\
\hline - & ليتواصل مدير المدرسة مع الطلاب الإنطوائيين. & $r, 09$ & $1, r \wedge$. & $* * * \vee १, \leqslant \curlyvee \Gamma$ & $\vee 1, \Lambda$ & 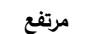 & 1 \\
\hline 7 & ليقدر مدير المدرسة التضحيات التي يقدمها الطلاب لزملائهه. & $r, r \wedge$ & $1, \ldots 7$ & ****E,YYY & 10,7 & متوسط & 11 \\
\hline $\mathrm{v}$ & يثجع مدير المدرسة إنثاء صفوف تقوبة تحت إثراف الطلاب أنفسهر. & $r, r_{0}$ &., 910 & $* * * \wedge, \leqslant \curlyvee 9$ & TV,. & متوسط & 9 \\
\hline$\Lambda$ & ليحرص على تكوين فرق العمل بين الطلاب لإنجاز الأعمال. & $r, r \wedge$ &., $9 \curlyvee \wedge$ & $* * * \wedge, r \cdot 1$ & $i v, \mathrm{~T}$ & متوسط & 0 \\
\hline 9 & |لتعاوني. مدير المدرسة المعلمين على إتباع استراتيجيات تدريسية معينة مثل التعلم & $r, \Delta r$ & $1, r+a$ & $* * * \vee १, \wedge \circ$ & $v \cdot, \tau$ & 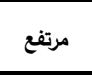 & $r$ \\
\hline 1. & يحرص مدير المدرسة على إقامة يوم مفتوح للطلاب. & $r, r q$ & 1,19 & $* * * r, r+1$ & TV,r & 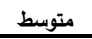 & $\mathrm{v}$ \\
\hline 11 & ليثجع مدير المدرسة على التبرع للجمعيات الخيربة والمحتاجين. & $r, r_{1}$ & $\cdot, \mathrm{V} \leqslant \mathrm{r}$ & $* * * 0$, * ४ & $r \leqslant, Y$ & متوسط & 14 \\
\hline ir & ليفعل مدير المدرسة يوم النشاط المدرسي. & $r, r \leq$ & $\cdot, 9 \vee \cdot$ & $* * * 4, \cdot \vee \vee_{0}$ & 74,1 & متوسط & 1. \\
\hline$i$ & يظهر مدير المدرسة اهتمام بمشاكل الطلاب فيما بينهح. & $r, r_{1}$ & $\cdot, \wedge \wedge 9$ & $* * * v, \wedge 0$. & $T \leqslant, Y$ & متوسط & $1 \leqslant$ \\
\hline $1 \leqslant$ & إيشجع مدير المدرسة العمل الفردي. & $r, 1 \leq$ & $\cdot, \wedge \varepsilon \cdot$ & $* * * \sqcap, \div, 1 \leqslant 9$ & $T r, \Lambda$ & متوسط & 10 \\
\hline 10 & يحث مدير المدرسة الطلاب على الاهتمام بمن حولهه. & $r, \leqslant 0$ & $1, r \div \wedge$ & $* * * \wedge \wedge, 0,0$ & 19, & 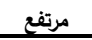 & $r$ \\
\hline & |إلمدرسية بدوية مدراء مدارس الموريتة المتوسطة في تفعيل النزعة الإجتماعية لدى ط & $r, r_{0}$ & $\cdot, 1 \times r$ & $* * 1,0, r_{0}$ & iv,. & متوسط & - \\
\hline
\end{tabular}

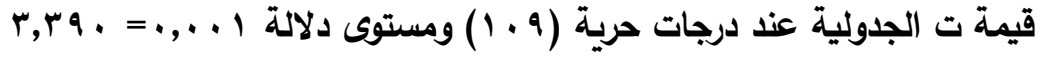

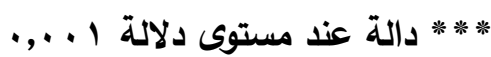

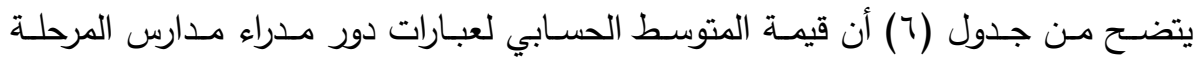

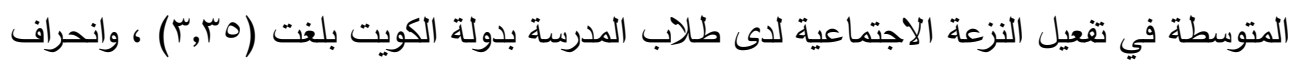

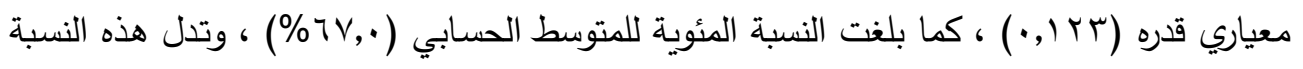


على أن دور مدراء مدارس المرحلة المتوسطة في تفعيل النزعة الاجتماعية لدى طلاب المدرسة

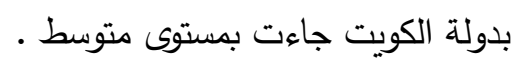
ومن ثم يرى الباحث أن تلك النسبة غير مرضية وغير كافية لتصبح درجة ممارسة مدراء

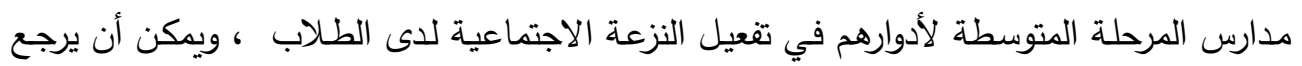
ذلك إلى ضعف شخصية المدير ، وعدم إدراكه لمدى أهمية دوره وتأثيره على الطلاب لتنمية النزعة لادئه

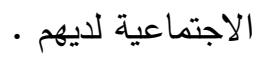
فجاءت الاستجابة على كل عبارات دور مدراء مدارس المرحلة المتوسطة في تفعيل النزعة

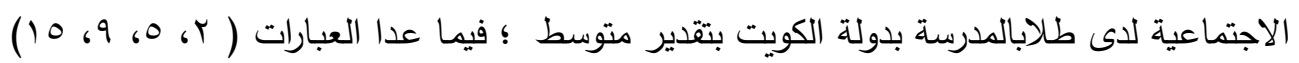

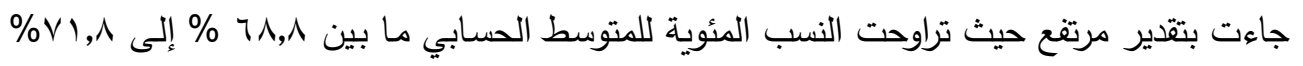
، ويمكن أن يرجع ذلك إلى إلمام المدير بأهمية التعاون وحث الطـلاب وتثجيعهم عليه وإدراكه.

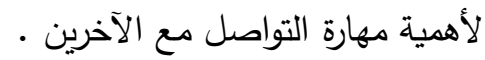

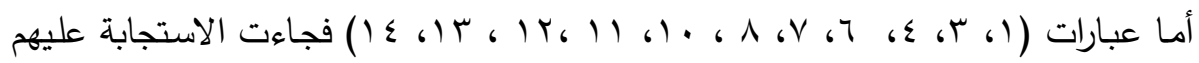

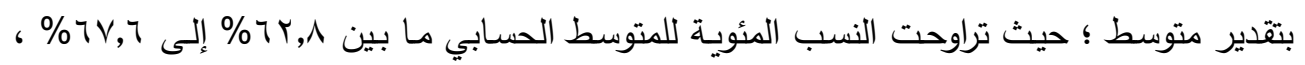

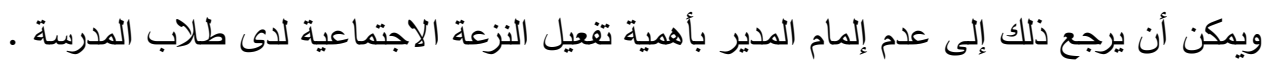
تحليل الفروق الإحصائية - بالنسبة المؤهل العلمي

للتعـرف علـى دلالمـة فـرق المتوسـط بـين اسـتجابات عينــة الدراســة مـن المؤهـل الجـامعي والدراسات العليا حول دور مدراء مدارس المرحلة المتوسطة في تفعيل النزعة الاجتماعية لدى طلاب

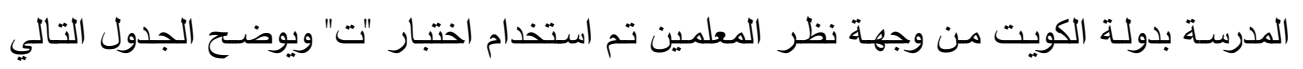
النتائج :

جدول (V) الفروق بين متوسط درجات دور مدراء مدارس المرحلة المتوسطة في تفعيل النزعة الاجتماعية لاى طلاب المدرسة وفقا للمؤهل العلمي من وجهة نظر المعلمين

\begin{tabular}{|c|c|c|c|c|c|c|c|}
\hline \multirow{2}{*}{ مصدر التباين } & \multicolumn{2}{|c|}{ جامعي ن = جا } & \multicolumn{2}{|c|}{ دراسات عليا ن = • ب } & \multirow{2}{*}{ قيمة ت } & \multirow{2}{*}{\multicolumn{2}{|c|}{ الدلالة }} \\
\hline & المتوسط & الانحراف & المتوسط & الانحراف & & & \\
\hline 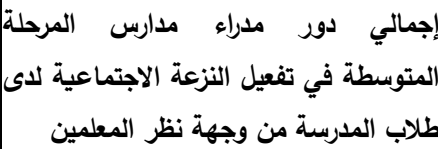 & $\leqslant \wedge, ৭ 9$ & $9, ד 1 Y$ & $\bullet Y, \wedge q$ & $\Lambda, Y r \Lambda$ & $r, \cdot V$. & $\cdot, \cdot \leq 1$ & $\cdot, .0$ \\
\hline
\end{tabular}




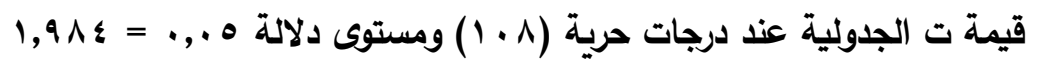

يوضح جدول (V) وجود فروق دالة إحصائياً بين متوسطي درجات دلاته الحاصلين على المؤهل

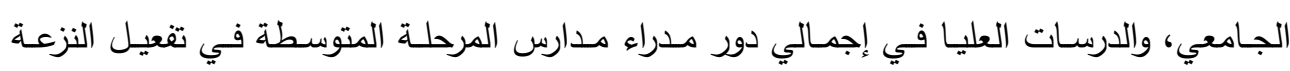

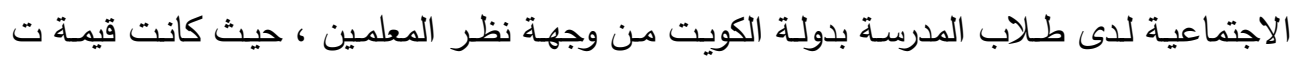

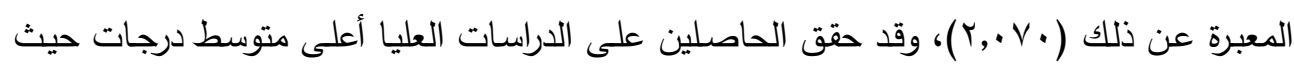

$$
\begin{aligned}
& \text { بلغت (A ) } \\
& \text { - سنوات الخبرة }
\end{aligned}
$$

للتعرف على دلالـة فرق المتوسط بين استجابات عينـة الدراسـة حول دور مدراء مدارس

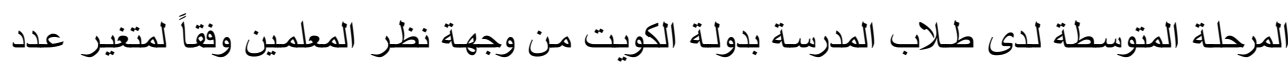
سنوات الخبرة تم استخدام اختبار تحليل التباين الأحادي ويوضح الجدول لدول التالي النتائج :

\begin{tabular}{|c|c|c|c|c|c|c|}
\hline البيان & 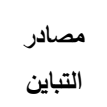 & المربعات & لدرجات & المربعات & قيمة ف & الدلالة \\
\hline \multirow{3}{*}{ الاجتماعية لاى طلاب المدرسة من وجهة نظر المراء المعلمينة في تفعيل النزعة } & المجموعات & $r \cdot \odot \wedge, r \wedge \wedge$ & $r$ & $10 r 9,1 \leqslant \varepsilon$ & \multirow{3}{*}{$r 0, r v i$} & \\
\hline & المجموعات & $r \leqslant \leqslant 9, \cdot r$. & $1 \cdot v$ & $Y, Y Y Y$ & & \\
\hline & الكلى & $90, v, r \backslash \wedge$ & 1.9 & & & \\
\hline
\end{tabular}
جدول (^) الفروق بين متوسط درجات دور مدراء مدارس المرحلة المتوسطة في تفعيل النزعة الإجتماعية لاى طلاب المدرسة وفقا لسنوات الخبرة من وجهة نظر المعلمين دوردين

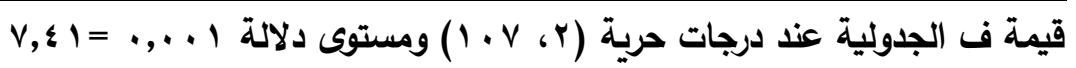

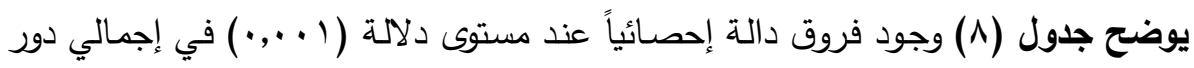

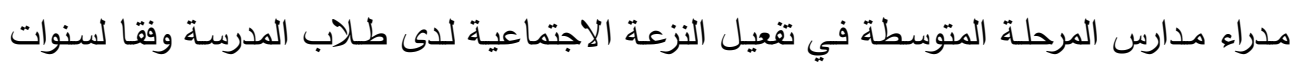

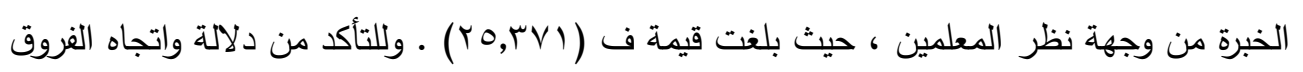

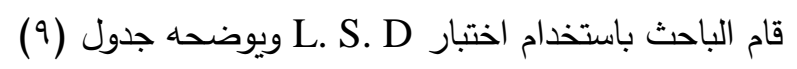

\begin{tabular}{|c|c|c|c|c|c|c|c|}
\hline المتغيرات & سنوات الخبرة & 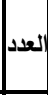 & الحسابي & الانعراف & سنوات & • من • إلى & • أكثر من سنوات \\
\hline إجمالي دور مدراء مدارس المرحلة المتوسطة & أقل من • سنوات & 17 & $\mu \wedge, 19$ & $11, \varepsilon .9$ & - & & \\
\hline
\end{tabular}
الجدول (9) اتجاه الفروق بين المجاميع الثلاثة لسنوات الخبرة وفقا لدور مدراء مدارس المرحلة

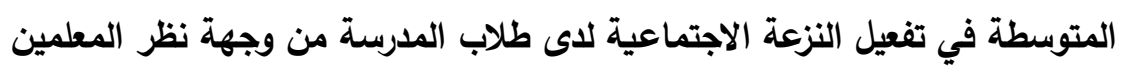




\begin{tabular}{|c|c|c|c|c|c|c|c|}
\hline تفعيل النزعة الاجتماعية لاى & من • إلى • 1 سنوات & 0 : & $0 ., 4$ & $\uparrow, 0 \leqslant$ & ****।, r, $\leq \leq-$ & - & \\
\hline |المدرسة من وجهة نظر المعلمين & أكثر من · 1 سنوات & ؛. & $0 \leqslant, 0$. & $V, 07 Y$ & $* * *|7, r|-$ & $* \Gamma, \wedge \vee-$ & - \\
\hline
\end{tabular}

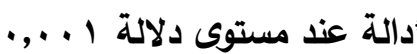
*دالة عند مستوى دلالة ه ه.,.

تم إجراء اختبار L.S.D للتعرف على اتجاه الفروق في إجمالي دور مدراء مدارس المرحلة

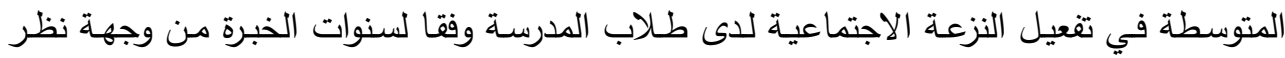

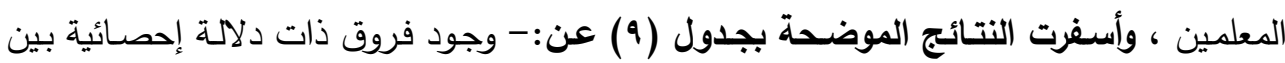

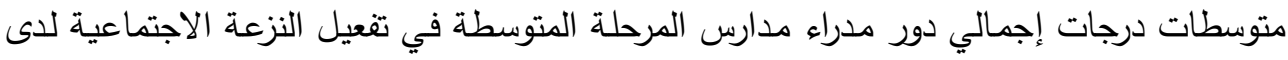

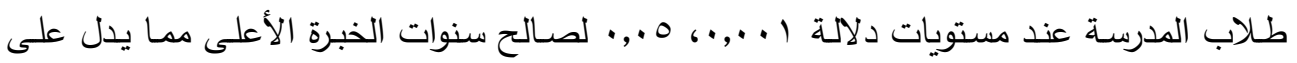
ضرورة الخبرة في تفعيل النزعة الاجتماعية . التوصيات

- تعزيز دور مدراء المدارس في تفعيل النزعـة الاجتماعيـة لدى الطلاب على جميع مستويات

$$
\text { - التعليم }
$$

- أعطاء أهية خاصة لتتمية النزعة الاجتماعية لدى طلاب مدارس دولة الكويت بجميع مراحلها

التعليمية الخاصة والحكومية .

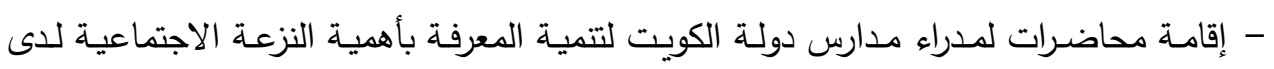

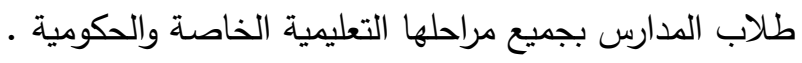




$$
\text { قائمة المر اجع }
$$

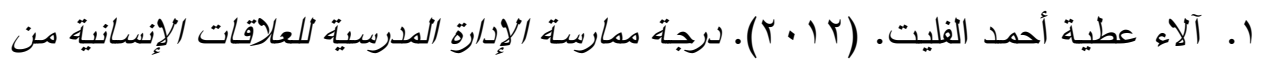

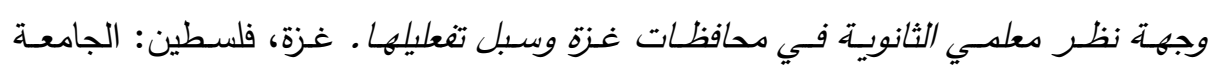

الاسلامية بغزة.

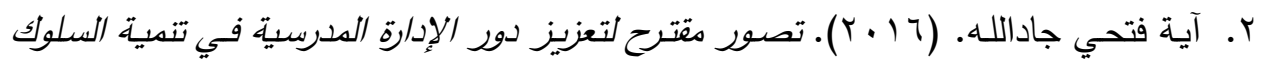

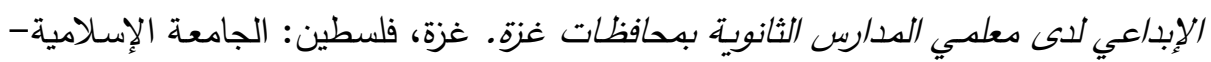

غزة.

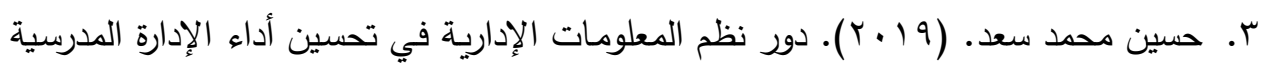

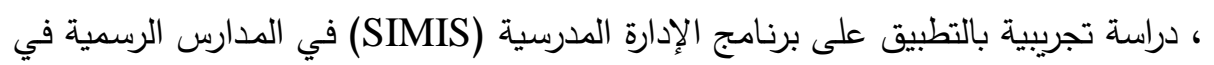

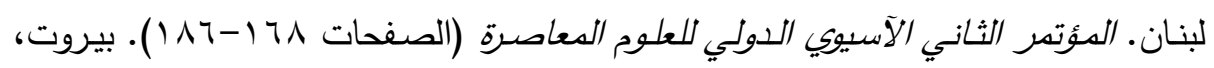

لبنان: معهد التتمية الاقتصادية والبحوث الاجتماعية (IKSAD).

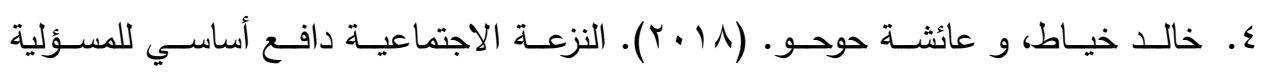

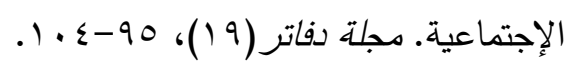

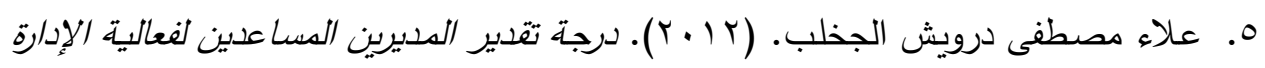

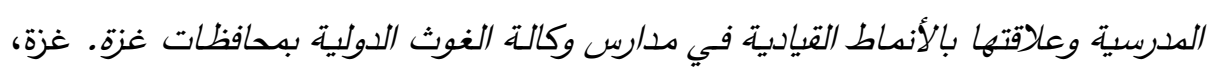

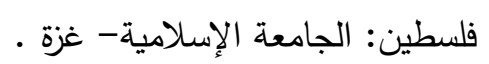

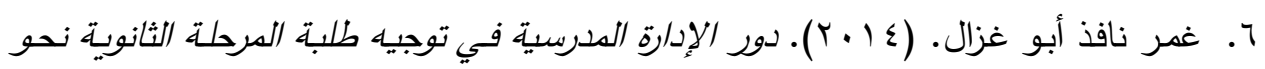

التعليم التقني ببحافظات غزة، وسبل تطويره. غزة، فلسطين: الجامعة الإسلامية بغزة.

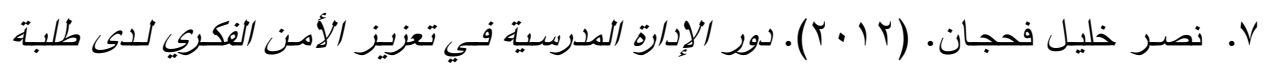

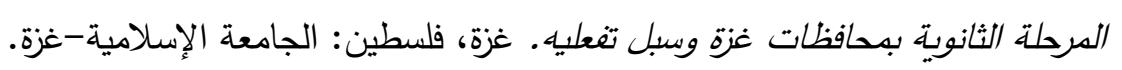

8. Aytaç, K. Y., \& Kartal, M. (2016). Analyzing the prosocial tendency of students studying at physical education and sports department. SHS Web of Conferences, 26, 1-7.

9. Azimpour, A., Neasi, A., Shehni-Yailagh, M., \& Arshadi, N. (2012). Validation of "Prosocial Tendencies Measure" in Iranian University Students. Journal of Life Science and Biomedicine, 2(2), 34-42.

10. Caprara, G. V., Kanacri, B. P., Gerbino, M., Zuffiano, A., Alessandri, G., Vecchio, G., et al. (2014). Positive effects of promoting prosocial behavior in early adolescence: Evidence from a school-based 
intervention. International Journal of Behavioral Development, 38(4), 386-396.

11. Carlo, G., \& Randall, B. A. (2002). The Development of a Measure of Prosocial Behaviors for Late Adolescents. Journal of Youth and Adolescence, 31(1), 31-44.

12. Gao, F., Yao, Y., Yao, C., Xiong, Y., Ma, H., \& Liu, H. (2019). The Status of Pro-social Tendency of Left-Behind Adolescents in China: How Family Function and Self-Esteem Affect Pro-social Tendencies. Frontiers in Psychology, 10, 1-13.

13. Hardy, S. A., Carlo, G., \& Roesch, S. C. (2010). Links Between Adolescents' Expected Parental Reactions and Prosocial Behavioral Tendencies: The Mediating Roleof Prosocial Values. Journal Youth Adolescence, 39, 84-95.

14. Kuswendi, U. (2019). TEACHER STRATEGY IN DEVELOPMENT PROSOCIAL BEHAVIOR OF STUDENTS IN ELEMENTARY SCHOOL. Journal of Elementary Education, 3(1), 7-16.

15. Lampridis, E., \& Papastylianou, D. (2014). Prosocial behavioural tendencies and orientation towards individualism-collectivism of Greek young adults. International Journal of Adolescence and Youth, 1-16.

16. Longobard, C., Settanni, i. M., Lin, S., \& Fabris, M. A. (2020). Student-teacher relationship quality and prosocial behaviour: The mediating role of academic achievement and a positive attitude towards school. British Journal of Educational Psycholog, 1-16.

17. Plenty, S., Ostberg, V., \& Modin, B. (2015). The role of psychosocial school conditions in adolescent prosocial behaviour. School Psychology International, 27, 1-18.

18. Quain, S., Yidana, X. D., Ambotumah, B. B., \& Mensah-Livivnstone, I. J. (2016). Pro-social Behavior amongst Students of Tertiary Institutions: An Explorative and a Quantitative approach. Journal of Education and Practice, 7, 26-33.

19. Rodrigues, J., Ulrich, N., Mussel, P., Carlo, G., \& Hewig, J. (2017). Measuring Prosocial Tendencies in Germany: Sources of Validity and Reliablity of the Revised Prosocial Tendency Measure. Frontiers in Psychology, 8, 1-17. 